\title{
Dumbbell Ossification
}

National Cancer Institute

\section{Source}

National Cancer Institute. Dumbbell Ossification. NCI Thesaurus. Code C124528.

A finding of a fusion of two approximately spherical primary ossification centers at or near the mid-line through an ossified bony bridge, as indicated by staining. 